\title{
First Records of the Invasive "Upside-down Jellyfish", Cassiopea (Cnidaria: Scyphozoa: Rhizostomeae: Cassiopeidae), from Coastal Lakes of New South Wales, Australia
}

\author{
StePhen J. KeABle And Shane T. AhyOnG* \\ Marine Invertebrates, Australian Museum Research Institute, \\ 1 William Street, Sydney, NSW 2010, Australia \\ stephen.keable@austmus.gov.au ·shane.ahyong@austmus.gov.au
}

\begin{abstract}
Scyphozoans of the genus Cassiopea (Cassiopeidae) are notable for their unusual benthic habit of lying upside-down with tentacles facing upwards, resulting in their common name, "upsidedown jellyfish". In Australia, five named species of Cassiopea have been recorded from the tropical north. Cassiopea are frequently noted worldwide as invasive species and here, we report the first records of the genus and family from temperate eastern Australia on the basis of specimens collected from two widely separated coastal lakes, Wallis Lake and Lake Illawarra; these specimens represent southern range extensions of the genus by approximately $600 \mathrm{~km}$ and $900 \mathrm{~km}$, respectively. Cassiopea from Lake Illawarra and Wallis Lake appear to represent different species, which we assign to C. ndrosia and C. cf. maremetens, respectively, noting morphological discrepancies from published accounts.
\end{abstract}

KEYwORDS. Introduced species, coastal lake, Cassiopea, Wallis Lake, Lake Illawarra, New South Wales

KeABLe, StePhen J., AND SHANE T. AHYONG. 2016. First records of the invasive "upside-down jellyfish", Cassiopea (Cnidaria: Scyphozoa: Rhizostomeae: Cassiopeidae), from coastal lakes of New South Wales, Australia. Records of the Australian Museum 68(1): 23-30.

The medusa stage of the scyphozoan, Cassiopea (Cassiopeidae), is a distinctive marine or estuarine jellyfish, notable for its unusual, inverted, largely sedentary and benthic behaviour, imparting the common name "upside-down jellyfish". This lifestyle typically involves the jellyfish lying in sheltered, shallow water with the aboral surface of the exumbrella facing downward onto sediments and the oral arms above. This posture and niche provides sunlight to algal endosymbionts (zooxanthellae) within the tissues although the jellyfish are also suspension feeding carnivores (Verde \& McCloskey, 1998; Schembri et al., 2009; Marsh \&
Slack-Smith, 2010). The severity of stings to humans from Cassiopea has been variably reported from mild or absent to severe (Southcott, 1982; Marsh \& Slack-Smith, 2010).

Although Cassiopea is readily recognized, the species level taxonomy is confused and requires reappraisal (Holland et al., 2004). Worldwide, at least 11 species are currently recognized: Cassiopea andromeda (Forskål, 1775), C. depressa Haeckel, 1880, C. frondosa (Pallas, 1774), C. medusa Light, 1914, C. maremetens Gershwin, Zeidler \& Davie, 2010, C. mertensi Brandt, 1838, C. ndrosia Agassiz \& Mayer, 1899, C. ornata Haeckel, 1880, C. xamachana

* author for correspondence 


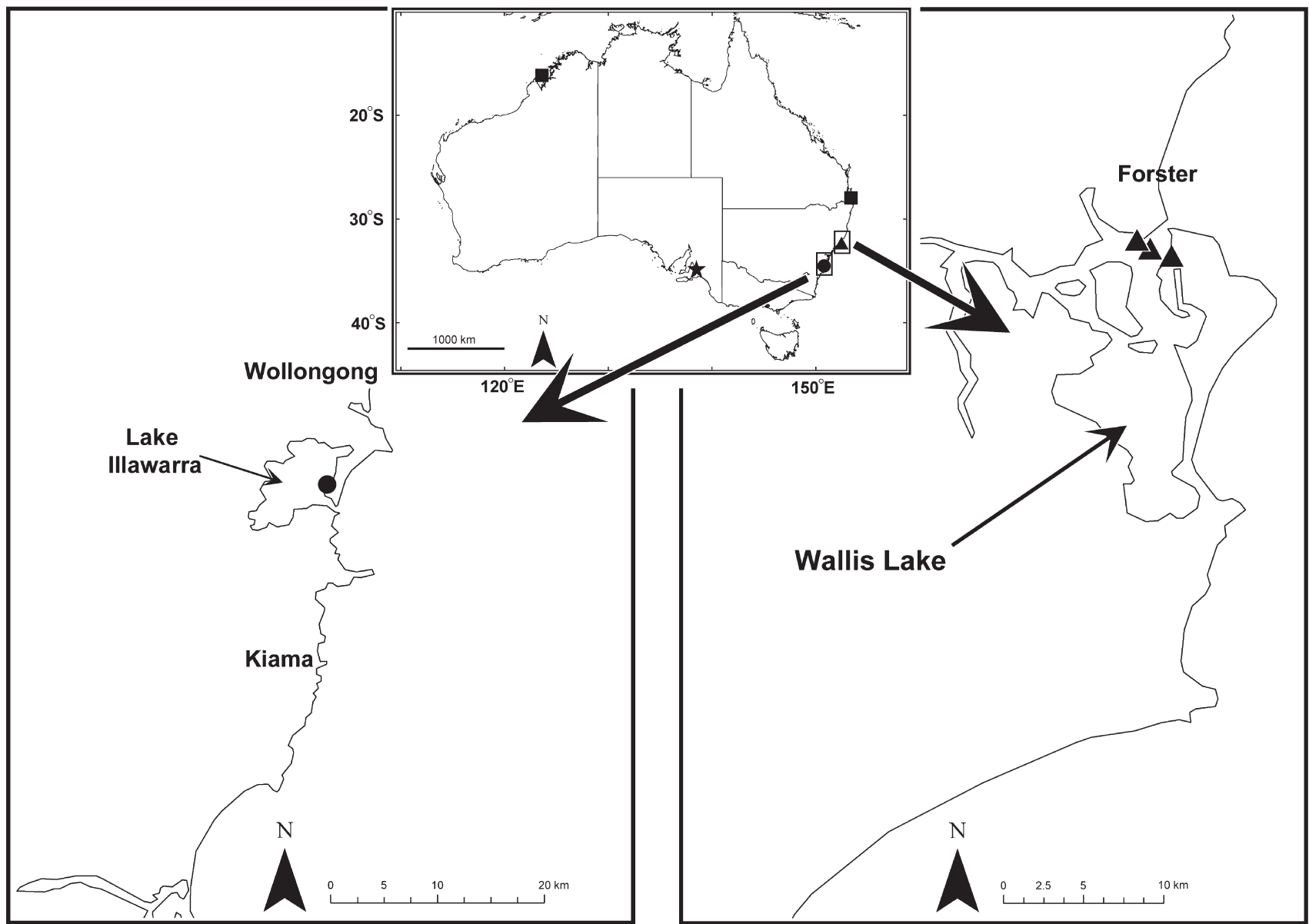

Figure 1. Location of previous southern records of Cassiopea from Australia (squares) and new localities reported here (circles and triangles), star represents anomalous record from Torrens Island Power Station.

Bigelow, 1892 (Gershwin et al., 2010; WoRMS, 2014). Unfortunately, the correct name applicable to specimens from various locations is problematic (Holland et al., 2004) and undescribed species are known (Gershwin et al., 2010). Therefore, few species of Cassiopea can presently be accurately identified.

The genus is widely distributed in the tropics (Holland et al., 2004) but also acknowledged as globally invasive (Graham \& Bayha, 2007). As early as 1886, C. andromeda from the Red Sea was recorded in the Suez Canal, and soon after in the Mediterranean Sea off Cyprus; today it is known from the Aegean coast of Turkey (Gülșahin \& Tarkan, 2012) and the central Mediterranean Sea off Malta (Schembri et al., 2009). Other incursions are recorded from Hawaii (Holland et al., 2004). In Australia, five named species or subspecies (C. andromeda andromeda, C. andromeda baduensis, $C$. maremetens, $C$. ndrosia, $C$. ornata) and two undescribed species have been reported (Gershwin et al., 2010). Péron \& Lesueur (1810) described Cassiopea dieuphila from northwestern Australia but its taxonomic status is presently indeterminate. Previous southernmost Australian records of Cassiopea (Fig. 1) are from Queensland and Western Australia, north of approximately $27^{\circ} 58^{\prime} \mathrm{S}$ on the east coast and $16^{\circ} 08^{\prime} \mathrm{S}$ on the west coast (Atlas of Living Australia, 2014). An additional anomalous record of $C$. ndrosia from
Angas Inlet, near Adelaide, South Australia (approximately $34^{\circ} 48^{\prime} \mathrm{S} 138^{\circ} 32^{\prime} \mathrm{E}$ ) is associated with the warm water outlet of the Torrens Island Power Station where temperatures are raised $5-8^{\circ} \mathrm{C}$ above ambient (Southcott, 1982).

Here, we report the sudden, recent appearance of medusae of Cassiopea from two shallow, widely separated, coastal lakes on the central east coast of Australia based on both sightings and preserved specimens. These are the first records of Cassiopea and Cassiopeidae from temperate eastern Australia.

\section{Materials and methods}

In 2013 and 2014, the authors were contacted through colleagues by concerned members of the public seeking to identify jellyfish that had appeared in large numbers in their local waterways (Lake Illawarra, 2013, and Wallis Lake, 2014; Fig. 1) and considered unusual. Subsequently, examples of these jellyfish were collected and deposited in the collections of the Australian Museum (AM). Whole specimens are fixed in $4-10 \%$ formalin but non-formalin fixed frozen tissue samples have also been retained for genetic studies currently in progress. Specimen measurements indicate bell diameter (bd). The synonymy of $C$. ndrosia is restricted to the original citation and Australian records. 


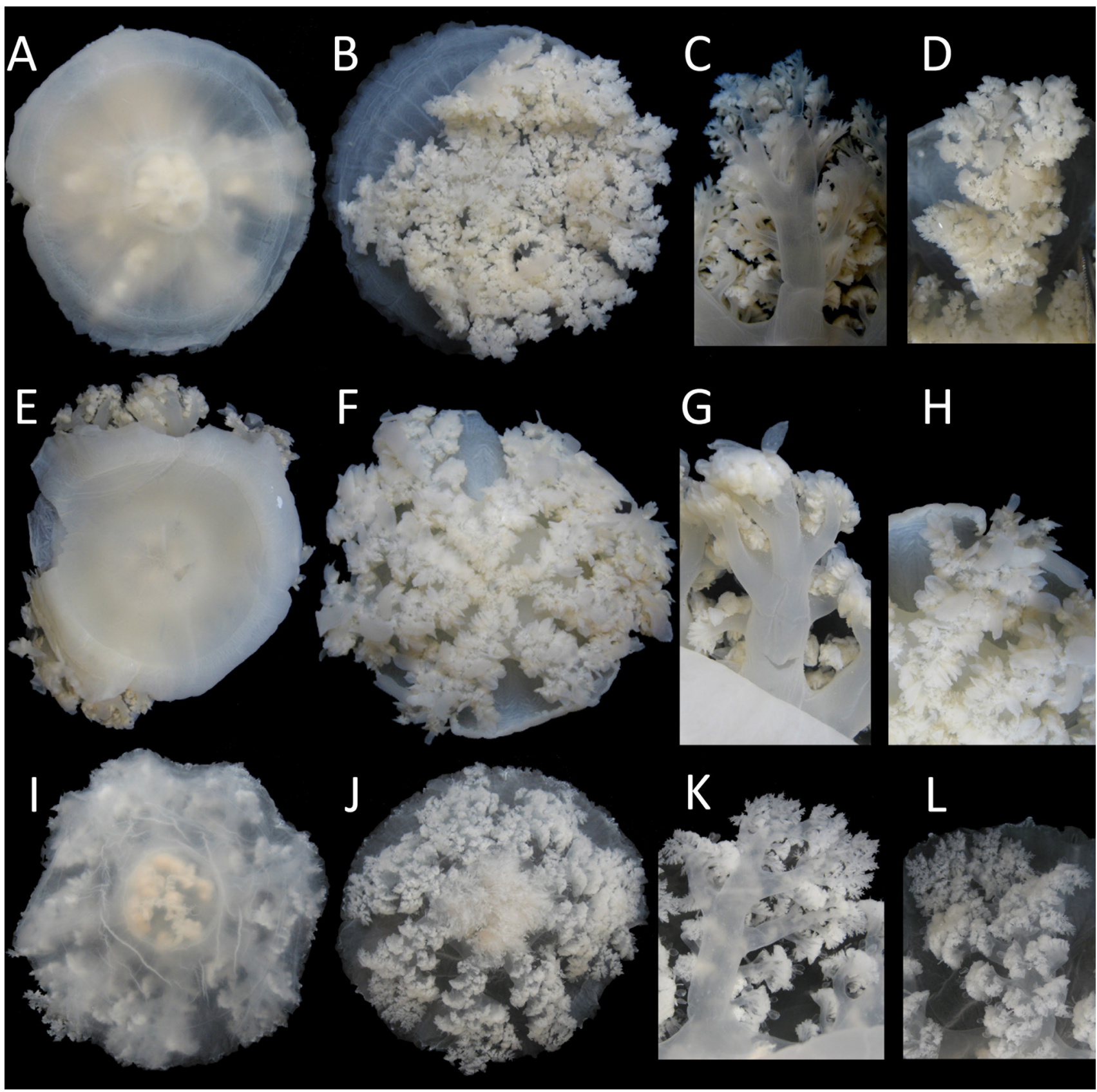

Figure 2. (A-D) Cassiopea ndrosia, bd $80 \mathrm{~mm}$, Lake Illawarra, AM G.18075. (E-H) Cassiopea cf. maremetens, bd $80 \mathrm{~mm}$, Wallis Lake, AM G.18155. (I-L) Cassiopea maremetens, bd 110 mm, Moreton Bay, paratype, QM G.6645. A, E, I, aboral surface; $B, F$, J, oral surface; $C, G, K$, aboral view of oral arm; $D, H, L$, oral view of oral arm.

\section{Taxonomy}

A taxonomic revision of Cassiopea is needed as there are a number of difficulties in recognizing species within the genus with currently used character suites (Holland, 2004; Gershwin et al., 2010; Shapiro, 2014). On the basis, however, of characters highlighted by Mayer (1910) and Gershwin et al. (2010) in comparison with paratypes of $C$. maremetens in the Queensland Museum (QM G.6645, Fig. 2I-L) and other specimens in the collections of the Australian Museum (AM), it is apparent that two forms are present in the samples from New South Wales, identified here as $C$. ndrosia (Lake Illawarra) and C. cf. maremetens (Wallis Lake).

\section{Cassiopeidae Tilesius, 1831}

Cassiopea ndrosia Agassiz \& Mayer, 1899

Figs 2A-D, 3A-B

Cassiopea ndrosia Agassiz \& Mayer, 1899: 175, pl. 14, figs 45, 46; Stiasny, 1934: 913-921; Kramp, 1965: 265; Southcott, 1982: 159, pls. 15.3, 15.4; Gershwin et al., 2010: 91

Material examined. AM G.18074, 1 specimen, from bottom of canal through "Jetties By The Lake Lifestyle Village" at Windang Road, Lake Illawarra, New South Wales, Australia, 


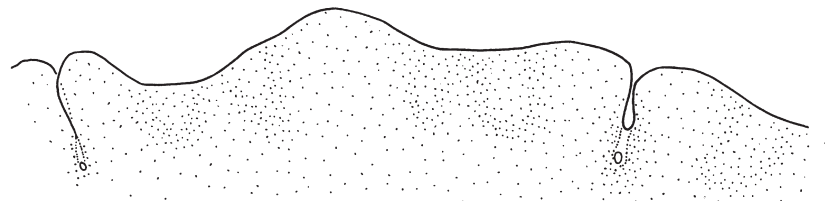

A

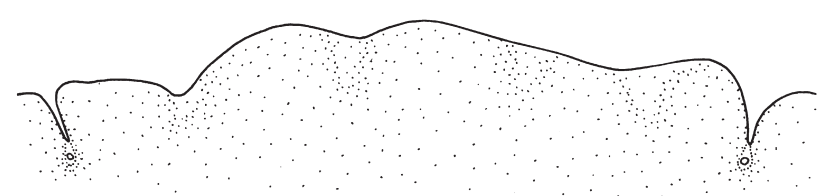

B
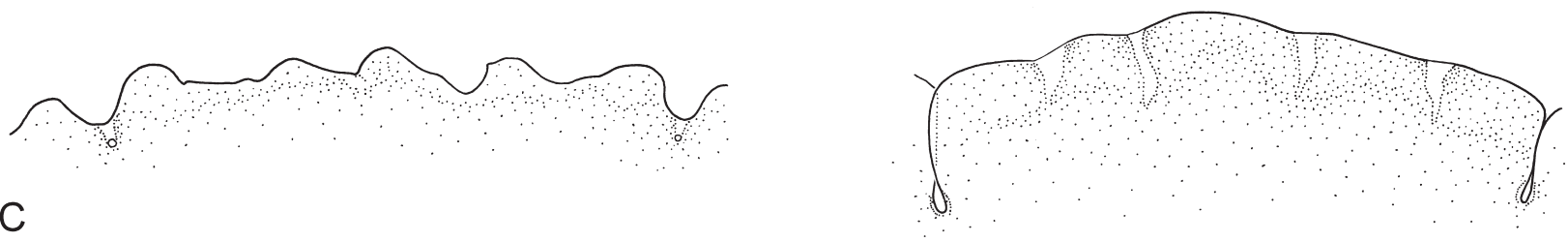

Figure 3. Lappets, oral view. (A) Cassiopea ndrosia, Lake Illawarra, bd 80 mm, AM G.18075. (B) Cassiopea ndrosia, bd 100 mm, Hayman Island, AM G. 13568. (C) Cassiopea cf. maremetens, bd 90 mm, Wallis Lake, AM G.18156. (D) Cassiopea maremetens, paratype, bd $110 \mathrm{~mm}$, Moreton Bay, QM G6645. Scale $=5.0 \mathrm{~mm}$.

34³1'36"S 15051'53"E, 0-1 m, M. Cameron, 8 May 2013; AM G.18075, 1 specimen ( $80 \mathrm{~mm})$, locality data as for G.18074; AM G.13568, 3 specimens (90-120 mm), Hayman Island, Whitsunday Passage, Queensland, 2003'S $148^{\circ} 53^{\prime} \mathrm{E}$, tidal flat, coll. F. A. McNeill, January 1933.

Remarks. The Lake Illawarra specimens, collected in 2013, conform well to $C$. ndrosia according to diagnostic characters indicated by Mayer (1910), Southcott (1982), Gershwin et al. (2010: tab. 9) and comparative specimens from Queensland (AM P.13568; originally reported by Stiasny, 1934). The "pinnate" branching of the oral arms (i.e., with lateral arms opposing each other on the primary arm) is the most significant distinction from $C$. maremetens in which the lateral arms "alternate" in position along the primary arm (see Fig. 2C for $C$. ndrosia from Lake Illawarra versus Fig. $2 \mathrm{~K}$ for $C$. maremetens). Additionally, the oral arms are subequally branched just distal of the midpoint of the total arm length in the material from Lake Illawarra, a condition found in $C$. maremetens only on the distal extremity of the oral arms due to the arrangement of alternate branching of the proximal lateral arms. The vesicles are elongate and leafshaped, of varying size, and numerous, especially toward the centre. Numbers of these vesicles are relatively small and no longer than the width of the oral arms, however, initially giving the impression that relatively fewer vesicles are present until examined under magnification. The Lake Illawarra and Queensland (Hayman Island) specimens agree closely and correspond to the current concept of $C$. ndrosia (see Mayer, 1910; Gershwin et al., 2010). Cassiopea ndrosia, first described from Fiji, is currently attributed a wide distribution in the central and western Pacific, from French Polynesia to Australia and Japan (Kramp, 1965); records, however, require confirmation (Holland et al., 2004; Gershwin et al., 2010). In Australia, C. ndrosia has been reported from Queensland (Torres Strait, the Gold Coast, Hayman Island; Stiasny, 1934; Kramp, 1965) and South Australia (Angas Inlet; Southcott, 1982).

Gershwin et al. (2010) noted the very close similarity between $C$. ndrosia and $C$. maremetens, with the chief differences recognized in the branching of the oral arms (pinnate versus alternate), and shape and number of lappets per paramere (1-2 indistinctly lobed versus 4 square, deeply incised); we question the latter distinction below under the account of $C$. cf. maremetens.

The collector of the Lake Illawarra specimens noted this jellyfish started appearing and multiplying two weeks prior to the samples being obtained. Over 100 individuals were observed at this time at the same location - a small, shallow, artificial canal (8-10 m wide, approximately $100 \mathrm{~m}$ long, less than $1 \mathrm{~m}$ deep) within a residential village on the Lake Illawarra foreshore (Fig. 4A). Water temperatures measured daily within the canal for over a week while the jellyfish were present ranged from 17 to $22^{\circ} \mathrm{C}$ but within two months of collection, and the onset of cooler winter weather (water temperature not measured), the population disappeared (M. Cameron, pers. comm.). A check of the area in May 2014 and discussion with local residents living next to the canal indicates the jellyfish have not reappeared at this location. Other sites along the shoreline within Lake Illawarra were also inspected in May 2014 without encountering any Cassiopea.

\section{Cassiopea cf. maremetens Gershwin, Zeidler \& Davie, 2010}

$$
\text { Figs 2E-H, 3C, 4E,F }
$$

Material examined. AM G.18137, 1 specimen, in channel splitting Godwin Island approximately one third distance from southern shore, Breckenridge Channel, Wallis Lake, New South Wales, Australia, 32¹1'45"S 152²9'56"E, R. Pearce, 15 August 2014. AM G.18138, 1 specimen, collection data as for G.18137. AM G.18139, 11 specimens, collection data as for G.18137. AM G.18143-18155, single specimens; AM G.18156, 13 specimens, Pipers Creek, behind Smugglers Cove Caravan Park, Wallis Lake, New South Wales, Australia, 32 ${ }^{\circ} 12^{\prime} 00^{\prime \prime S} 152^{\circ} 30^{\prime} 39^{\prime \prime E}$, R. Pearce, 18 September 2014. AM G.18181-18183, 4 specimens, inlet on south east side of Mather Island, Wallis Lake, New South Wales, Australia, 32॰11'26"S 152²9'36"E, S. J. Keable \& A. D. Hegedus, 28 April 2015. AM G.18184, 1 specimen, 

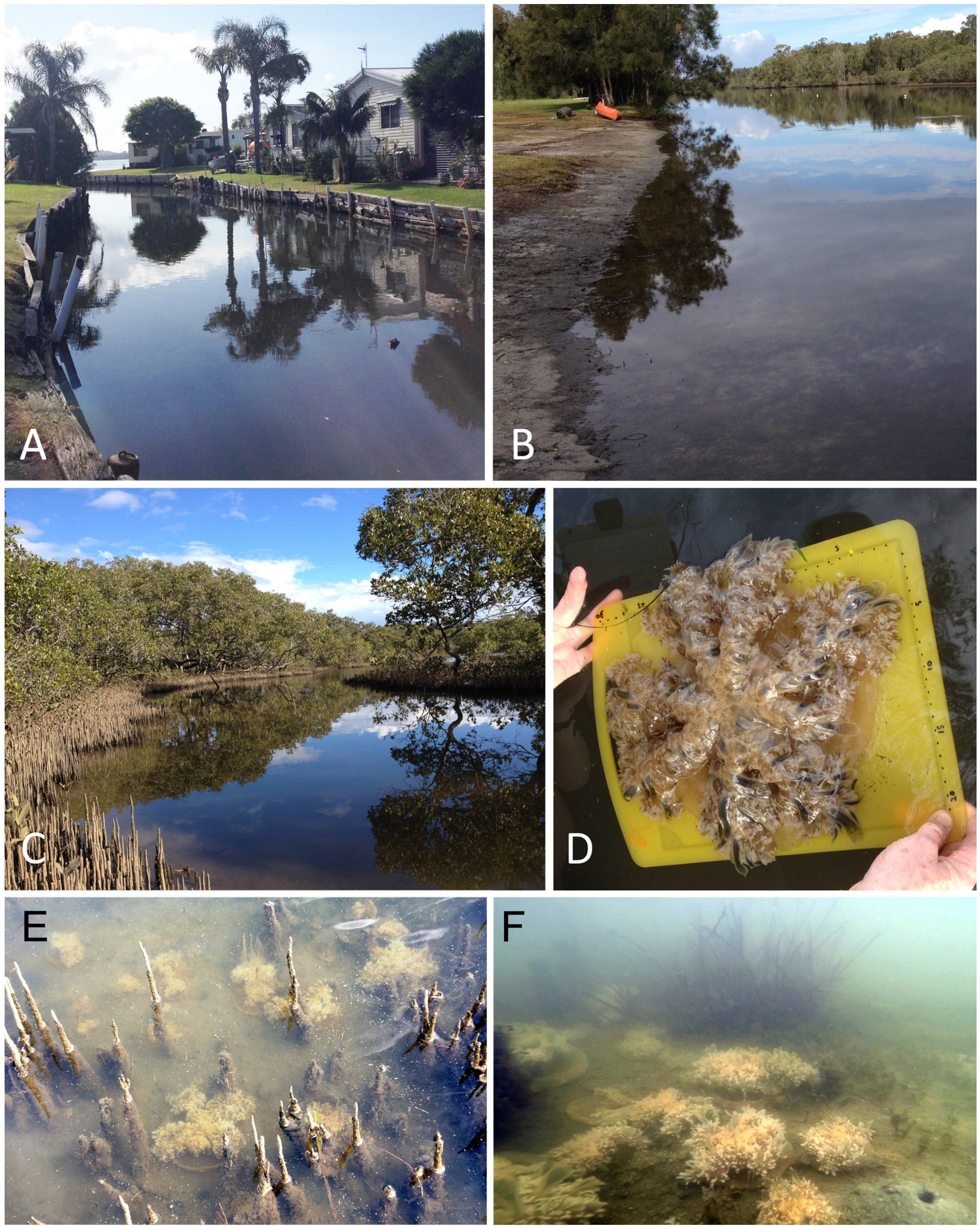

Figure 4. (A) Collection site for Cassiopea ndrosia from Lake Illawarra, canal through "Jetties By The Lake Lifestyle Village" looking toward lake. (B) Collection site for Cassiopea cf. maremetens from Pipers Creek, Wallis Lake, looking toward lake. (C) collection site for Cassiopea cf. maremetens from inlet on south east side of Mather Island, Wallis Lake, looking toward lake. (D) field measurement of bell diameter of c. $210 \mathrm{~mm}$ for Cassiopea cf. maremetens from Pipers Creek, Wallis Lake. (E-F) Aggregation of Cassiopea cf. maremetens at inlet on southeast side of Mather Island, Wallis Lake from above and below water surface, respectively. 
Pipers Creek within Smugglers Cove Caravan Park, Wallis Lake, New South Wales, Australia, 32¹1'58"S 152³0'39"E, S. J. Keable \& A. Murray, 30 April 2015. Bell diameter 35 mm (AM G.18182) to 210 mm (AM G.18139).

Comparative material of $\boldsymbol{C}$. maremetens. QM G6645, 3 paratypes (110-130 mm), Mud Island, Moreton Bay, Queensland, C. Wallace, 8 April 1972.

Remarks. The Wallis Lake specimens appear to be closest to $C$. maremetens Gershwin, Zeidler \& Davie, 2010, from Queensland (Figs 2I-L, 3D) (type locality, Lake Magellan, southwest of Caloundra, 26 $49^{\circ} 42^{\prime \prime S ~} 153^{\circ} 06^{\prime} 48.6^{\prime \prime E}$ ), with which they agree in most respects including exumbrella conformation, branching pattern of the oral tentacles and the numbers of rhopalia (19-21) (Gershwin et al., 2010). The material from Wallis Lake (Fig. 2G) agrees with type material of C. maremetens (QM G6645; Fig. 2K), and most noticeably differs from the Lake Illawarra specimens (Fig. $2 \mathrm{C}$ ), in having alternating (i.e., non-opposing) rather than pinnate lateral branches along the length of the oral arms and lacking a distinct subequal bifurcation just distal to the midpoint of the primary arm. They differ, however, from both $C$. maremetens sensu stricto and $C$. ndrosia in the presence of numerous, large, conspicuous vesicles along the length of these arms (compare Fig. 2H and Fig. 2D [C. ndrosia, Lake Illawarra] and Fig. 2L [C. maremetens]). The vesicles are variably leaf shaped (generally slightly broader in the distal half, maximum width approximately one-third length), and generally as wide as the lateral arm branches. The presence of the numerous large vesicles on the oral arms is the most significant distinction between the Wallis Lake specimens and $C$. maremetens sensu stricto, which has few or no vesicles. Gershwin et al. (2010), however, noted they could not adequately assess the significance of the presence or absence of vesicles in their material, whether a polymorphism or indicative of an additional unrecognized species. Just as Gershwin et al. (2010) observed no correlation between body size and presence of vesicles on the oral arms in C. maremetens, the vesicles in the Wallis Lake specimens are similarly numerous across the size range.

Significantly, our Wallis Lake specimens also differ from the description of $C$. maremetens in the lappet shape and arrangement (Fig. 3C-D). Ocelli are present in the Wallis Lake specimens, absent in $C$. maremetens. The margin of the parameres in the Wallis Lake specimens are sinuous, resulting in 4-5 low, rounded lobes (Fig. 3C). In contrast, the lappets of $C$. maremetens are reported as square and deeply incised, with four per paramere (Gershwin et al., 2010). Close examination of paratypes of C. maremetens, however, revealed the squared, apparently deep incisions are bridged by transparent exumbrella membrane (Fig. 3D). Thus, instead of being deeply incised, the outline of the lappets of $C$. maremetens (at least in the paratypes examined) is actually essentially sinuous and indistinctly lobate, much like that of $C$. ndrosia. The lappets in the Wallis Lake material differ from $C$. maremetens in having a more strongly sinuous margin with more numerous lobes per paramere. The differences in lappet shape and vesicle complement in comparison to $C$. maremetens suggest that the Wallis Lake specimens may represent a separate, possibly undescribed species. Pending further study, however, we tentatively identify our material as $C$. cf. maremetens to highlight its similarity to C. maremetens. Cassiopea maremetens sensu stricto is presently known from Bentinck Island, Gulf of Carpentaria, Queensland (c. 1703'34"S 139 $29^{\prime} 09^{\prime \prime E}$ ) to Moreton Bay on the Queensland east coast $\left(27^{\circ} 48^{\prime} \mathrm{S}\right.$ $\left.153^{\circ} 24^{\prime} \mathrm{E}\right)$. Reports of $C$. andromeda from Southport, Queensland $\left(27^{\circ} 58^{\prime} \mathrm{S} 153^{\circ} 25^{\prime} \mathrm{E}\right)$, just south of Moreton Bay, may also represent C. maremetens (Gershwin et al., 2010).

The original collector of Cassiopea $\mathrm{cf}$. maremetens from Wallis Lake first observed these jellyfish "in their hundreds" in Pipers Creek in 2009. The 2014 outbreak in the vicinity of Godwin Island (reported as "in large numbers within a small area"), documented here with specimens, was noticed on or near 2 August 2014 although specimens were not collected until 15 August 2014. Specimens of $C$. cf. maremetens were obtained again from the same location in Pipers Creek in September 2014.

Subsequent fieldwork in Wallis Lake in April 2015 confirmed the continued presence of $C$. cf. maremetens in Pipers Creek (Fig. 4B) and at a third locality within the lake adjacent to the shore at Mather Island (Fig. 4C). A 75 $\mathrm{m}$ transect line was placed randomly along the shoreline in both these locations and Cassiopea within $1 \mathrm{~m}$ of the shore along this distance were counted. Five randomly selected individuals from each transect were also measured for bell diameter. At Pipers Creek, 30 individuals were present along the transect, the bell diameter of the individuals measured ranged from 120 to $210 \mathrm{~mm}$ (Fig. 4D) with a mean of 170 $\mathrm{mm}$. At Mather Island 24 individuals were present along the transect, those measured ranged in size from 40-70 $\mathrm{mm}$ with a mean of $53 \mathrm{~mm}$. Distribution of Cassiopea appeared patchy. Outside the transects, dense aggregations were observed (Fig. 4E,F) with up to 35 per square metre at Mather Island. A water temperature of $21.5^{\circ} \mathrm{C}$ and a salinity of 28.7 parts per thousand was recorded during the Mather Island transect and a salinity of 12.1 parts per thousand at Pipers Creek. Cassiopea were observed lying with the aboral surface resting on very soft sediment in depths of 10-100 cm.

\section{Discussion}

The impacts (both ecological and economic) and mechanisms behind invasions and population explosions of jellyfish have received considerable recent interest (Graham \& Bayha, 2007; Gershwin, 2013; Pitt \& Lucas, 2014), influencing, for example, commercial fisheries, tourism and trophic structures. Species of Cassiopea feature in these reports as a globally invasive genus (see references cited above).

Cassiopea has not previously been recorded from New South Wales. Pitt et al. (2006) note jellyfish as the most conspicuous animals in Lake Illawarra and indicate the three species most commonly seen as Catostylus mosaicus, Phyllorhiza punctata and Aurelia aurita but not Cassiopea. Similarly, other scyphozoans such as Catostylus mosaicus have been documented from Wallis Lake (Pitt \& Kingsford, 2000) but not Cassiopea.

The samples reported here, therefore, represent a range extension for Cassiopea of approximately $600 \mathrm{~km}$ (Wallis Lake) to $900 \mathrm{~km}$ (Lake Illawarra) southward of the previous southern instance on the east Australian coast, Southport, Queensland. Given the lack of previous records, the apparently sudden appearance in large numbers is significant.

We do not discount the role of normal environmental change in driving changes in species' ranges. However, Cassiopea are not considered to have strong natural dispersal 
capabilities (Holland et al., 2004) so it is highly plausible that anthropogenic influences are involved. Given the isolated and significantly disjunct occurrences of the two forms recorded here, that at least one of the present forms does not appear referable to known Australian species, and the genus is conspicuous where it occurs, the new records from New South Wales do appear to represent new introductions. Even if the Wallis Lake form is referable to true C. maremetens, the absence of records from intermediate localities in New South Wales is consistent with human mediated translocation. Different factors may also be implicated in the different situations of Wallis Lake compared to Lake Illawarra. Vectors suggested for anthropogenic transport of Cassiopea include shipping (through biofouling or ballast water release), intentional or unintentional direct release and via "live rock" from aquaria (Holland et al., 2004; Graham \& Bayha, 2007; Schembri et al., 2009). Both lakes have considerable recreational and other domestic vessel traffic, and Lake Illawarra is close to a major population centre, Wollongong and commercial port, Port Kembla. Increased water temperatures associated with global warming or a perturbation of the East Australian Current could also be involved, although one would predict the occurrence of Cassiopea from intermediate localities between southern Queensland and Wallis Lake-Lake Illawarra.

The presence of Cassiopea medusae in Lake Illawarra currently appears to be ephemeral, but the dormant reproductive potential of the polyp stage of jellyfish (Gershwin, 2013) means another outbreak could occur again in the future. Conversely, Cassiopea appears to be established in Wallis Lake where it is continuously present over consecutive seasons. Given the amenity, economic asset and ecological benefits these waterways provide and the possible negative impacts invasive jellyfish are known to have, it is imperative that these outbreaks are studied further, and the vectors for translocation identified. Moreover, taxonomic revision of the genus is urgently required in order that incursions can be accurately recognized and tracked. We hope publication of these initial records will stimulate further investigations.
Acknowledgments. Mr M. Cameron and Ms R. Pearce are thanked for their concern in reporting these records and obtaining specimens for us. We also appreciate our colleagues Julian Pepperell (Pepperell Research \& Consulting Pty Ltd), Mark McGrouther (Australian Museum) and Kirk Dahle (NSW Department of Primary Industries) for bringing the initial reports to our attention. Alexandra Hegedus provided technical support in obtaining and curating the specimens documented, Anna Murray assisted in the field and Michael Elliott constructed the maps used in Fig. 1. Merrick Eckins, Queensland Museum, kindly arranged the loan of specimens of $C$. maremetens. Thanks go to Bella Galil and Pat Hutchings for constructive comments on the manuscript. This is a contribution from the Australian Museum Research Institute.

\section{References}

ABRS (Australian Biological Resources Study). 2014. Australian Faunal Directory. (Accessed November 2015). http://www.environment.gov.au/biodiversity/abrs/online-resources/fauna/afd/home

Agassiz, A., and A. G. Mayer. 1899. Acalephs from the Fiji Islands. Bulletin of the Museum of Comparative Zoology at Harvard University 32(9): 157-189, pls 1-17.

Atlas of Living Australia. 2014. Cassiopea. (Accessed November 2015).

http://www.ala.org.au

Gershwin, L., W. Zeidler, and P. J. F. Davie. 2010. Medusae (Cnidaria) of Moreton Bay, Queensland, Australia. In Proceedings of the Thirteenth International Marine Biological Workshop, the Marine Fauna and Flora of Moreton Bay, Queensland, ed. P. J. F. Davie, and J. A. Phillips. Memoirs of the Queensland Museum 54(3): 47-108.

Gershwin, L. 2013. Stung! On Jellyfish Blooms and the Future of the Ocean. Chicago: The University of Chicago Press, 456 pp. http://dx.doi.org/10.7208/chicago/9780226020242.001.0001

Gülșahin, N., and A. N. Tarkan. 2012. Occurrence of the alien jellyfish Cassiopea andromeda (Scyphozoa: Rhizostomeae: Cassiopeidae) in Hisarönü Bay, Muğla, Turkey. Biharean Biologist 6(2): 132-133.

Graham, W. M., and K. M. Bayha. 2007. Biological invasions by marine jellyfish. In Ecological Studies, volume 193: Biological Invasions, ed. W. Nentwig, pp. 239-255. Berlin: Springer-Verlag. http://dx.doi.org/10.1007/978-3-540-36920-2_14

Holland, B. S., M. N. Dawson, G. L. Crow, and D. K. Hofmann. 2004. Global phylogeography of Cassiopea (Scyphozoa: Rhizostomeae): molecular evidence for cryptic species and multiple invasions of the Hawaiian Islands. Marine Biology 145: 1119-1128.

http://dx.doi.org/10.1007/s00227-004-1409-4

Kramp, P. L. 1965. Some medusae (mainly Scyphomedusae) from Australian coastal waters. Transactions of the Royal Society of South Australia 89: 257-278, pls. 1-3.

Marsh, L., and S. Slack-Smith. 2010. Field Guide to Sea Stingers and Other Venomous and Poisonous Marine Invertebrates of Western Australia. Perth: Western Australia Museum, 248 pp.

Mayer, A. G. 1910. Medusae of the World. Volume III. The Scyphomedusae. Washington D.C.: Carnegie Institution of Washington, pp. 499-735, pl . 56-76.

Péron, F., and C. A. Lesueur. 1810. Tableau des caractères génériques et spécifiques de toutes les esp ces de méduses connues jusqu'à ce jour. Annales du Muséum d'Histoire naturelle, Paris 14(24): 325-366

Pitt, K. A., and M. J. Kingsford. 2000. Geographic separation of stocks of the edible jellyfish Catostylus mosaicus (Rhizostomeae) in New South Wales, Australia. Marine Ecology Progress Series 196: 143-155.

http://dx.doi.org/10.3354/meps196143 
Pitt, K. A, K. Koop, D. Rissik, and M. J. Kingsford. 2006. The ecology of scyphozoan jellyfish in Lake Illawarra. Wetlands (Australia) 21(2): 118-126.

Pitt, K. A., and C. H. Lucas, eds. 2014. Jellyfish Blooms. New York: Springer, $304 \mathrm{pp}$.

http://dx.doi.org/10.1007/978-94-007-7015-7

Schembri, P. J., A. Deidun, and P. J. Vella. 2009. First record of Cassiopea andromeda (Scyphozoa: Rhizostomeae: Cassiopeidae) from the central Mediterranean Sea. Marine Biodiversity Records 3: $1-2$.

Southcott, R. V. 1982. Jellyfishes (Classes Scyphozoa and Hydrozoa). In Marine invertebrates of Southern Australia. Part I, ed. S. A. Shepherd and I. M. Thomas. Adelaide: Government Printer, pp. 115-159.

Stiasny, G. 1934. Ueber Cassiopea ndrosia Ag. + May. aus den australischen Gewässern. Koninklijke Akademie van Wetenschappen te Amsterdam 36(10) (1933): 913-921.
Verde, E. A., and L. R. McCloskey. 1998. Production, respiration, and photophysiology of the mangrove jellyfish Cassiopea xamachana symbiotic with zooxanthellae: effect of jellyfish size and season. Marine Ecology Progress Series 168: 147-162. http://dx.doi.org/10.3354/meps 168147

WoRMS (World Register Of Marine Species). 2014. Cassiopea. (Accessed November 2015).

http://marinespecies.org

Manuscript submitted 6 December 2015, revised 22 March 2016, and accepted 24 March 2016. 